\title{
Features of the Functional Status and Cytokine Profile of Patients with Chronic Heart Failure in Combination with Chronic Obstructive Pulmonary Disease
}

\author{
Roman E. Tokmachev, PhD; Andrey Ya. Kravchenko, PhD, ScD; \\ Andrey V. Budnevsky, PhD, ScD; Evgeniy S. Ovsyannikov, PhD, ScD*; \\ Evgeniy V. Tokmachev, PhD; Tatiana A. Chernik \\ Voronezh State Medical University named after N.N. Burdenko \\ Voronezh, the Russian Federation
}

\begin{abstract}
The purpose of this research was to study the effect of COPD on the functional status and cytokine profile of patients with chronic heart failure (CHF) with different ejection fraction (EF).

Methods and Results: The study involved 240 patients diagnosed with CHF (mean age of $72.4 \pm 8.7$ years). Among them, 80 patients were diagnosed with CHF and COPD. Depending on the presence of COPD, the patients were divided into two groups: Group 1 included 160 patients with CHF without COPD; Group 2 included CHF 80 patients with COPD. According to the value of LVEF, each of the two groups was divided into two more subgroups: In Group 1, CHFpEF (EF $\geq 50 \%$ ) was recorded in 69 patients (Subgroup 1) and CHFrFV (EF $<50 \%$ ) in 91 patients (Subgroup 2). In Group 2, CHFpEF was observed in 36 patients (Subgroup 3 ) and CHFrEF in 44 patients (Subgroup 4). The 6-minute walk distance (6MWD) was measured in meters and compared with the proper $6 \mathrm{MWD}$ (i). All patients included in the study underwent the Borg test to assess dyspnea after 6MWT. The serum levels of NTproBNP, hs-CRP, IL-1 $\beta$, IL-6, and TNF- $\alpha$ were determined using an automatic analyzer IMMULITE 2000 (Siemens Diagnostics, USA) and quantitative ELISA kits. The patients with CHFpEF had higher levels of hs-CRP, pro-inflammatory cytokines than patients with CHFrEF. The combination of COPD and CHF amplifies systemic inflammation (hs-CRP, proinflammatory cytokines) and myocardial remodeling processes (NT-proBNP) in comparison with the isolated course of CHF. COPD negatively affects the functional status of patients with $\mathrm{CHF}$ with different $\mathrm{EF}$ by lower values of $6 \mathrm{MWD}, 6 \mathrm{MWD} / 6 \mathrm{MWD}$ (i) ratio, and higher results on the Borg dyspnea test. International Journal of Biomedicine. 2021;11(1):9-13.)
\end{abstract}

Key Words: chronic heart failure $\bullet$ ejection fraction $\bullet$ COPD $\bullet$ cytokines

For citation: Tokmachev RE, Kravchenko AYa, Budnevsky AV, Ovsyannikov ES, Tokmachev EV, Chernik TA. Features of the Functional Status and Cytokine Profile of Patients with Chronic Heart Failure in Combination with Chronic Obstructive Pulmonary Disease. International Journal of Biomedicine. 2021;11(1):9-13. doi:10.21103/Article11(1)_OA1

\section{Abbreviations}

6MWT, the 6-minute walking test; 6MWD, the 6-minute walk distance; CHF, chronic heart failure; COPD, chronic obstructive pulmonary disease; CHFrEF, CHF with reduced EF, CHFpEF, CHF with preserved EF; EF, ejection fraction; hs-CRP, highsensitivity C-reactive protein; HR, heart rate; IL, interleukin; LVEF, left ventricular EF; NT-proBNP, N-terminal pro-brain natriuretic peptide.

\section{Introduction}

With the increase in life expectancy (both of patients with cardiovascular disease and people in general), chronic heart failure (CHF) is becoming more widespread. CHF decompensation plays a dominant role among the reasons for hospitalization in cardiology departments, especially among patients over 65 years of age.(1) In the USA and European countries, more than 1 million patients are hospitalized annually for CHF. The annual mortality rate of outpatients 
with CHF is $7 \%$, and of those hospitalized - $17 \%$. ${ }^{(2)}$ The prognosis for such patients is significantly worsened when $\mathrm{CHF}$ is combined with other diseases. ${ }^{(3,4)}$

Difficulties in diagnosing CHF in patients with COPD, and the choice of tactics and methods of therapy in recent years, determine the increased scientific interest in the study of the cardiorespiratory continuum. It is believed that COPD affects from $25 \%$ to $42 \%$ of CHF patients. ${ }^{(5-7)}$ The comorbid course of these pathologies is associated with an increased risk of readmission and death.

Respiratory failure is traditionally considered the leading cause of death in COPD patients, but this judgment is valid only for the severe course of the disease. In patients with mild and moderate forms of COPD, patients with cardiovascular disease come first in the structure of mortality. The risk of cardiovascular death in COPD patients is 2-3 times higher than in the population. Thus, Sin et al. ${ }^{(8)}$ found that for every $10 \%$ decrease in $\mathrm{FEV}_{1}$, the risk of developing a non-fatal coronary event increases by almost $20 \%$, overall mortality by $14 \%$, and cardiovascular mortality by $28 \%$. According to the TORCH study, the causes of death of COPD patients can be represented as follows: $27 \%$ of deaths are due to cardiovascular complications, $35 \%$ to respiratory causes, $21 \%$ are associated with malignant neoplasms, and $10 \%$ for a number of other reasons. ${ }^{(9)}$ In the remaining $7 \%$ of cases, the cause of death was not established.

The relationship between the mechanisms of the development of COPD and patients with cardiovascular disease is studied from every angle. The general mechanisms of etiopathogenesis include systemic inflammation, oxidative stress, and endothelial dysfunction. ${ }^{(10-12)}$ The development of systemic inflammation is associated with the release of proinflammatory cytokines into the bloodstream, products of lipid peroxidation that induce overproduction of a number of other mediators. Thus, in the development of CHFpEF, a special role is assigned to excessive activation of the sympathetic-adrenal system and the subsequent increase in the synthesis of proinflammatory cytokines (TNF- $\alpha$, IL-1). This, in turn, leads to an increase in the activity of nitric oxide synthases and production of NO in tissues, which has negative effects on the cardiovascular system (apoptosis and fibrosis of cardiomyocytes, direct toxic effect on the myocardium). In this regard, identifying three categories of patients with HF (with preserved, borderline and reduced LVEF) is of particular relevance to study the effect of systemic inflammation on the clinical course, functional status and prognosis of patients with comorbid COPD and CHF with different LVEF. Thus, the high comorbidity of $\mathrm{CHF}$ and COPD and the increased risk of unfavorable outcomes in this combination of pathologies suggest further study of the mechanisms of CHF progression, and improvement of diagnostic methods and treatment principles for this category of patients.

The purpose of this research was to study the effect of COPD on the functional status and cytokine profile of patients with CHF with different EF.

\section{Materials and Methods}

The study involved 240 patients diagnosed with $\mathrm{CHF}$ (134 men and 106 women, mean age of $72.4 \pm 8.7$ years), included in the regional register of CHF patients in the Voronezh region. Among them, 80 patients (48[60\%] men and 32[40\%] women) aged between 40 and 80 years were diagnosed with CHF and COPD (GOLD 2, group D) without exacerbation. Depending on the presence of COPD, the patients were divided into two groups: Group 1 included 160 patients with CHF who had no signs of COPD; Group 2 included 80 patients with a comorbid course of CHF and COPD. All patients with COPD corresponded to the "phenotype with frequent exacerbations" ( 2 or more per year) and required antibiotic therapy and/ or glucocorticosteroids. The diagnosis of COPD was made on the basis of an integral assessment of symptoms, history, objective status, and spirometry data, according to GOLD, revision 2019. According to the value of LVEF, each of the two groups was divided into two more subgroups: In Group 1, CHFpEF (EF $\geq 50 \%$ ) was recorded in 69 patients (Subgroup 1) and $\mathrm{CHFrFV}(\mathrm{EF}<50 \%)$ in 91 patients (Subgroup 2). In Group 2, CHFpEF was observed in 36 patients (Subgroup 3) and CHFrEF in 44 patients (Subgroup 4). The diagnosis of CHF was established according to 2016 ESC Guidelines for the diagnosis and treatment of acute and chronic heart failure. The functional class (FC) of CHF was determined according to the NYHA classification (1994), based on the results of the 6MWT.

The non-inclusion criteria for Groups 1 and 2 were the presence of chronic kidney disease ( $3 \mathrm{~b}$ stages and higher), diabetes mellitus or taking hypoglycemic drugs, permanent atrial fibrillation, anemia, diseases of musculoskeletal system (coxarthrosis, gonarthrosis, etc., reducing motor activity), obesity (2-3 classes) and other severe somatic pathologies.

From the moment of inclusion in the study, patients were examined weekly by researchers - a cardiologist and a pulmonologist - to make sure there were no symptoms of $\mathrm{CHF}$ decompensation and exacerbation of COPD. After 12 weeks, the study participants underwent a standard examination, which included clinical, laboratory and instrumental methods. Exercise tolerance was determined using a complex of cardiorespiratory analysis and register of patients with $\left.\mathrm{CHF}^{(13,14}\right)$ and 6MWT.

The 6MWD was measured in meters and compared with the proper $6 \mathrm{MWD}(\mathrm{i})$. The $6 \mathrm{MWD}(\mathrm{i})$ value was calculated using the formulas below, which take into account age and BMI. The formula for calculating $6 \mathrm{MWD}(\mathrm{i})$ for men: $6 \mathrm{MWD}(\mathrm{i})=1140$ $5.61 \times$ BMI-6.94×age. The 6 MWD (i) value for women was defined as: $6 \mathrm{MWD}(\mathrm{i})=\left(1017-6.24 \times \mathrm{BMI}^{-5.83 \times \text { age }^{(1)}}\right.$

The serum levels of NT-proBNP, hs-CRP, IL-1 $\beta$, IL6 , and TNF- $\alpha$ were determined using an automatic analyzer IMMULITE 2000 (Siemens Diagnostics, USA) and quantitative ELISA kits: NT-proBNP - using the Biomedica human NT-proBNP Sandwich ELISA kit (Austria), hs-CRP using the SRB-IFA-BEST highly sensitive kit (Vector-Best, Russia), IL-1 $\beta$ using the Interleukin-1 beta - ELISA-BEST kit (Vector-Best, Russia), IL-6 using the Interleukin-6- ELISABEST kit (Vector-Best, Russia), and TNF- $\alpha$ using the alphaTNF-ELISA-BEST (Vector-Best, Russia). Comprehensive two-dimensional and Doppler echocardiography were performed using an EPIQ5 ultrasound system (Phillips, USA) equipped with S5-1 Pure-Wave Cardiac Transducer. All patients included in the study underwent the Borg test to assess dyspnea after 6MWT. 
All patients received treatment according to the standards for the treatment of CHF and COPD.

The study was approved by the Ethics Committee of Voronezh State Medical University named after N.N. Burdenko. Written informed consent was obtained from each patient.

All data was evaluated with STATGRAPHICS Plus 5.1. Baseline characteristics were summarized as frequencies and percentages for categorical variables and as mean $\pm \mathrm{SD}$, median (Me) and interquartile range (IQR; 25th to 75th percentiles) for continuous variables. Student's unpaired t-test was used to compare two groups for data with normal distribution. Mann-Whitney U test was used to compare means of 2 groups of variables not normally distributed. A probability value of $P<0.05$ was considered statistically significant.

\section{Results}

The median NT-proBNP value in Subgroup 2 was 1804(608-4908) ng/L, which significantly exceeded its value in Subgroup 1 - 980(301;2677) ng/L $(P<0.001)$. The median NT-proBNP level in Subgroup 4 was 2046(1103;2806) ng/L, which also exceeded its value in Subgroup 3 - 1280(601;3150) ng/L $(P<0.001)$ (Fig. 1). This result allows us to conclude that the NT-proBNP biomarker does not lose its sensitivity in the case of a combined course of COPD and CHF.

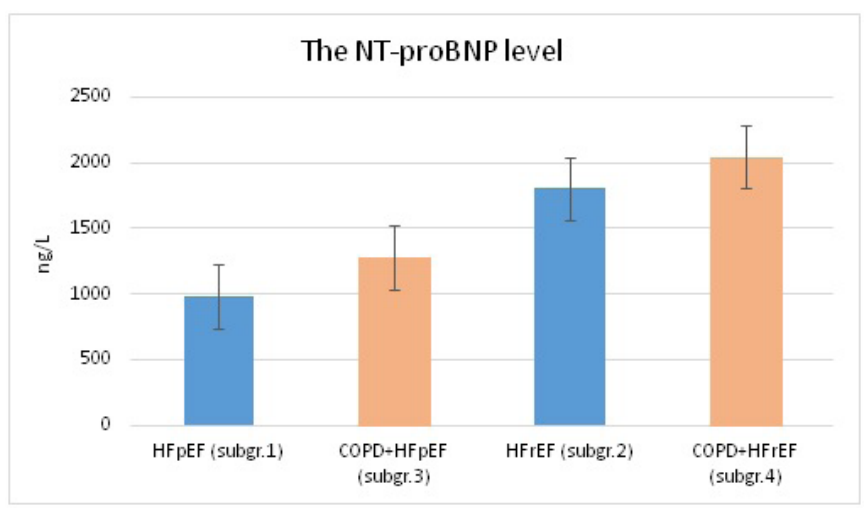

Fig. 1. The NT-proBNP level in the study subgroups.

It was also noted that in patients of Group 2 who had a combination of COPD and CHF, the NT-proBNP level, equal to $1593(601 ; 3150) \mathrm{ng} / \mathrm{L}$, was higher than in Group 1 patients with isolated CHF - 1064(301;4908) ng/L $(P=0.049)$.

The level of hs-CRP, known as a biomarker of endogenous inflammatory processes, in patients with $\mathrm{CHFpEF}$ was $3.4(1.2 ; 8.1) \mathrm{mg} / \mathrm{L}$, while in patients with $\mathrm{CHFrEF}$ it was statistically significantly lower - 2.9(1.6;5.4) mg/l $(P<0.001)$. The level of hs-CRP in Subgroup 4 was $4.1(2.3 ; 15.6) \mathrm{mg} / \mathrm{L}$, which was also lower than in patients of Subgroup 3 4.8(1.9;13.5) ng/L $(P<0.001)$. The hs-CRP levels obtained in the study in isolated cardiac pathology in patients with various NYHA FC indicate an increase comparable to that in patients with FCII $(3.2[1.2 ; 7.1] \mathrm{mg} / \mathrm{l})$, a more pronounced FCIII $(3.3[1.4 ; 7.8] \mathrm{mg} / \mathrm{l})$ and severe FCIV $(3.5[1.8 ; 8.1] \mathrm{mg} / \mathrm{l})$ $(P=0.06)$ (Fig. 2).
We found an increase in the level of pro-inflammatory cytokines in all studied subgroups (Table 1). At the same time, the content of IL-1 $\beta$, IL- 6 , and TNF- $\alpha$ was significantly higher in Group 2.

A higher level of IL-1 $\beta$, IL-6, and TNF- $\alpha$, hs-CRP (Table 1) in Subgroups 1 and 3 compared with Subgroups 2 and 4 reflects how important the contribution of systemic inflammation is to the development and progression of heart failure. At the same time, a higher level of pro-inflammatory cytokines was observed in Group 2 than in Group 1, which demonstrates a close pathogenetic relationship between the two pathologies.

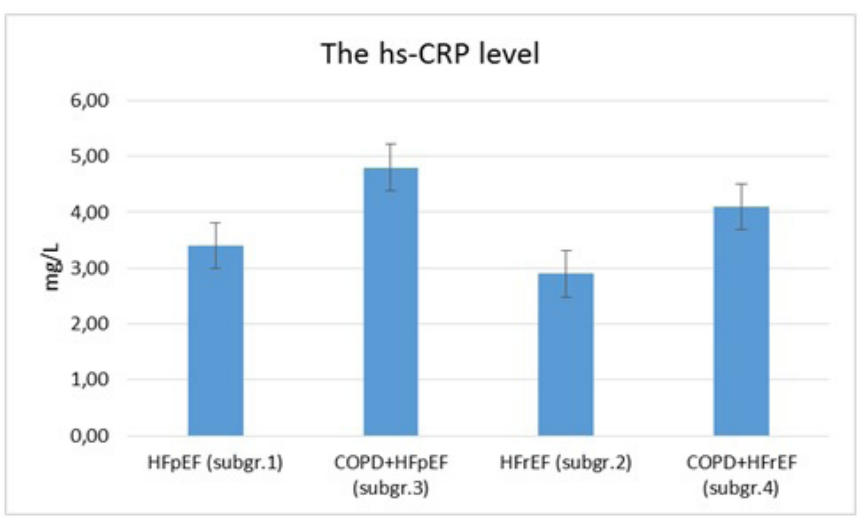

Fig. 2. The Hs-CRP level in the study subgroups.

Table 1.

Cytokine profile in study subgroups

\begin{tabular}{|c|c|c|c|c|c|c|}
\hline 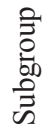 & IL-1 $\beta$ & $\begin{array}{l}\frac{0}{J} \\
\frac{\pi}{\pi} \\
2_{1}^{1}\end{array}$ & IL-6 & $\begin{array}{l}\stackrel{0}{3} \\
\stackrel{\pi}{\pi} \\
0^{1}\end{array}$ & TNF- $\alpha$ & $\begin{array}{l}\frac{0}{3} \\
\frac{\pi}{\pi} \\
0 \\
0\end{array}$ \\
\hline 1 & $121.9 \pm 25.4$ & \multirow{2}{*}{$\stackrel{0}{0}$} & $298.2 \pm 35.8$ & \multirow{2}{*}{$\begin{array}{l}0 \\
8 \\
8\end{array}$} & $163.4 \pm 27.2$ & \multirow{2}{*}{$\stackrel{+}{0}$} \\
\hline 2 & $103.1 \pm 21.0$ & & $186.5 \pm 29.6$ & & $143.0 \pm 24.9$ & \\
\hline 3 & $139.3 \pm 26.1^{*}$ & \multirow{2}{*}{$\begin{array}{l}\text { J } \\
\stackrel{0}{0}\end{array}$} & $408.3 \pm 61.3 *$ & \multirow{2}{*}{$\begin{array}{l}n \\
8 \\
0\end{array}$} & $256.8 \pm 33.7^{*}$ & \multirow{2}{*}{$\stackrel{\Omega}{0}$} \\
\hline 4 & $122.1 \pm 24.8^{\wedge}$ & & $312.7 \pm 41.1^{\wedge}$ & & $198.4 \pm 28.1^{\wedge}$ & \\
\hline
\end{tabular}

* $-P<0.05$ between Subgroups 1 and $3 ; \wedge_{-} P<0.01$ between Subgroups 2 and 4 .

The 6MWD level (Table 2) in patients with comorbid COPD and $\mathrm{CHF}$, regardless of $\mathrm{EF}$, was less than in $\mathrm{CHF}$ without COPD $(P<0.05$ in both cases $)$. This fact can be explained by a combination of obstructive and restrictive breathing disorders.

Assessment of the $6 \mathrm{MWD} / 6 \mathrm{MWD}$ (i) ratio showed that in Group 2, the average value of this indicator was significantly less than in Group 1, regardless of EF $(P<0.05$ in both cases). In previous studies, we found that in patients with COPD, a decrease in physical activity was apparently associated not only with lung dysfunction at rest, but also depends on a number of other factors. Thus, in COPD patients, a decrease in lean body mass is often observed, which is a 
consequence of systemic inflammation and muscle atrophy due to low physical activity. In turn, this study showed that the comorbid course of CHF and COPD is accompanied by a higher activity of pro-inflammatory cytokines than with isolated CHF. Therefore, it can be assumed that one of the components that reduce exercise tolerance in such patients is the activation of systemic subclinical inflammation, leading, among other things, to a decrease in lean body mass.

The values of heart rate both before and immediately after performing 6MWT in patients in the study groups did not differ significantly. At the same time, in the process of performing 6MWT, the device did not record any excess of the submaximal values of this parameter in any of the subjects.

Before the start of the test, the studied subgroups did not differ in the level of $\mathrm{SpO}_{2}$. However, this parameter was significantly lower in patients with $\mathrm{CHF}$ and COPD immediately after 6MWT, regardless of EF (Table 2). In turn, in patients in Subgroups 3 and 4 (CHF patients with COPD), higher scores on the Borg test, reflecting the degree of dyspnea after 6MWT, compared with Subgroups 1 and 2 (CHF patients without COPD), indicate a lower tolerance to physical activity (Table 2).

\section{Table 2.}

Comparative characteristics of $6 M W T$ parameters, dynamic pulse oximetry in patients in the studied subgroups

\begin{tabular}{|l|c|c|c|c|c|c|}
\hline \multicolumn{1}{|c|}{ Indicator } & Subgr. 1 & Subgr. 3 & $P_{1-3}$ & Subgr. 2 & Subgr. 4 & $P_{2-4}$ \\
\hline 6MWD, m & $\begin{array}{c}301.5 \\
\pm 153.5\end{array}$ & $\begin{array}{c}264.6 \\
\pm 120.6\end{array}$ & 0.04 & $\begin{array}{c}251.5 \\
\pm 183.5\end{array}$ & $\begin{array}{c}202.4 \\
\pm 130.2\end{array}$ & 0.03 \\
\hline 6MWD(i), \% & $\begin{array}{c}53.0 \\
\pm 29.2\end{array}$ & $\begin{array}{c}47.2 \\
\pm 25.6\end{array}$ & 0.01 & $\begin{array}{c}48.1 \\
\pm 30.5\end{array}$ & $\begin{array}{c}42.8 \\
\pm 22.4\end{array}$ & 0.02 \\
\hline $\begin{array}{l}\text { HR before } \\
\text { test, bpm }\end{array}$ & $\begin{array}{c}76.1 \\
\pm 15.2\end{array}$ & $\begin{array}{c}77.8 \\
\pm 17.3\end{array}$ & 0.18 & $\begin{array}{c}86.1 \\
\pm 15.2\end{array}$ & $\begin{array}{c}87.8 \\
\pm 17.3\end{array}$ & 0.16 \\
\hline $\begin{array}{l}\text { HR after } \\
\text { test, bpm }\end{array}$ & $\begin{array}{c}102.4 \\
\pm 17.5\end{array}$ & $\begin{array}{c}107.3 \\
\pm 18.8\end{array}$ & 0.15 & $\begin{array}{c}109.4 \\
\pm 17.2\end{array}$ & $\begin{array}{c}115.1 \\
\pm 14.8\end{array}$ & 0.15 \\
\hline $\begin{array}{l}\text { SpO2 before } \\
\text { test, \% }\end{array}$ & $\begin{array}{c}97.9 \\
\pm 2.0\end{array}$ & $\begin{array}{c}97.5 \\
\pm 2.1\end{array}$ & 0.12 & $\begin{array}{c}95.2 \\
\pm 2.4\end{array}$ & $\begin{array}{c}94.9 \\
\pm 2.6\end{array}$ & 0.26 \\
\hline $\begin{array}{l}\text { SpO2 after } \\
\text { test, \% }\end{array}$ & $\begin{array}{c}95.5 \\
\pm 3.0\end{array}$ & $\begin{array}{c}93.3 \\
\pm 3.1\end{array}$ & 0.001 & $\begin{array}{c}94.1 \\
\pm 3.3\end{array}$ & $\begin{array}{c}91.2 \\
\pm 2.5\end{array}$ & 0.001 \\
\hline $\begin{array}{l}\text { Borg test, } \\
\text { points }\end{array}$ & $\begin{array}{c}2.41 \\
\pm 0.17\end{array}$ & $\begin{array}{c}3.22 \\
\pm 0.29\end{array}$ & 0.01 & $\begin{array}{c}3.83 \\
\pm 0.32\end{array}$ & $\begin{array}{c}5.19 \\
\pm 0.37\end{array}$ & 0.001 \\
\hline
\end{tabular}

\section{Conclusion}

The patients with CHFpEF have higher levels of hsCRP, pro-inflammatory cytokines than patients with CHFrEF. This reflects more pronounced subclinical inflammation. The combination of COPD and CHF amplifies systemic inflammation(hs-CRP, proinflammatory cytokines) and myocardial remodeling processes (NT-proBNP) in comparison with the isolated course of CHF. COPD negatively affects the functional status of patients with CHF with different EF by lower values of $6 \mathrm{MWD}, 6 \mathrm{MWD} / 6 \mathrm{MWD}$ (i) ratio, and higher results on the Borg dyspnea test.

\section{Sources of Funding}

The reported study was supported by the Russian Federation President Council on Grants (Grant No. MK1776.2020.7).

\section{Competing Interests}

The authors declare that they have no competing interests.

\section{References}

1. Roger VL, Go AS, Lloyd-Jones DM, Benjamin EJ, Berry JD, Borden WB, Bravata DM, Dai S, Ford ES, Fox CS, Fullerton HJ, Gillespie C, Hailpern SM, Heit JA, Howard VJ, Kissela BM, Kittner SJ, Lackland DT, Lichtman JH, Lisabeth LD, Makuc DM, Marcus GM, Marelli A, Matchar DB, Moy CS, Mozaffarian D, Mussolino ME, Nichol G, Paynter NP, Soliman EZ, Sorlie PD, Sotoodehnia N, Turan TN, Virani SS, Wong ND, Woo D, Turner MB; American Heart Association Statistics Committee and Stroke Statistics Subcommittee. Executive summary: heart disease and stroke statistics--2012 update: a report from the American Heart Association. Circulation. 2012 Jan 3;125(1):188-97. doi: 10.1161/CIR.0b013e3182456d46. Erratum in: Circulation. 2012 Jun 5;125(22):e1001.

2. Maggioni AP, Dahlström U, Filippatos G, Chioncel O, Crespo Leiro M, Drozdz J, Fruhwald F, Gullestad L, Logeart D, Fabbri G, Urso R, Metra M, Parissis J, Persson H, Ponikowski P, Rauchhaus M, Voors AA, Nielsen OW, Zannad F, Tavazzi L; Heart Failure Association of the European Society of Cardiology (HFA). EURObservational Research Programme: regional differences and 1-year follow-up results of the Heart Failure Pilot Survey (ESC-HF Pilot). Eur J Heart Fail. 2013 Jul;15(7):808-17. doi: 10.1093/eurjhf/hft050.3.

3. Budnevsky AV, Malysh EY. [Clinico-Pathogenetic Relationship of Cardiovascular Diseases and Chronic Obstructive Pulmonary Disease]. Kardiologiia. 2017 Apr;57(4):89-93. [Article in Russian].

4. Drobysheva ES, Tokmachev RE, Budnevsky AV, Kravchenko AYa. [Predictive value of biomarkers of heart cachexia in chronic heart failure]. Kardiovaskulyarnaya Terapiya i Profilaktika. 2016; 15(4):80-83. [Article in Russian]. 5. Flu WJ, van Gestel YR, van Kuijk JP, Hoeks SE, Kuiper R, Verhagen HJ, Bax JJ, Sin DD, Poldermans D. Co-existence of COPD and left ventricular dysfunction in vascular surgery patients. Respir Med. 2010 May;104(5):690-6. doi: 10.1016/j. rmed.2009.11.013.

6. Cazzola M, Bettoncelli G, Sessa E, Cricelli C, Biscione G. Prevalence of comorbidities in patients with chronic obstructive pulmonary disease. Respiration. 2010;80(2):1129. doi: 10.1159/000281880.

7. Hawkins NM, Wang D, Petrie MC, Pfeffer MA, Swedberg K, Granger CB, Yusuf S, Solomon SD, Ostergren J, Michelson EL, Pocock SJ, Maggioni AP, McMurray JJ; CHARM Investigators and Committees. Baseline characteristics

*Corresponding author: Evgeniy $S$. Ovsyannikov, $P h D, S c D$. Department of faculty therapy, Voronezh State Medical University named after N.N. Burdenko. Voronezh, Russia. E-mail: ovses@, yandex.ru 
and outcomes of patients with heart failure receiving bronchodilators in the CHARM programme. Eur J Heart Fail. 2010 Jun;12(6):557-65. doi: 10.1093/eurjhf/hfq040.

8. Sin DD, Man SF. Chronic obstructive pulmonary disease as a risk factor for cardiovascular morbidity and mortality. Proc Am Thorac Soc. 2005;2(1):8-11. doi: 10.1513/pats.200404-032MS.

9. McGarvey LP, John M, Anderson JA, Zvarich M, Wise RA; TORCH Clinical Endpoint Committee. Ascertainment of cause-specific mortality in COPD: operations of the TORCH Clinical Endpoint Committee. Thorax. 2007 May;62(5):4115. doi: 10.1136/thx.2006.072348.

10. Budnevsky AV, Ovsyannikov ES, Labzhania NB. [Chronic obstructive pulmonary disease concurrent with metabolic syndrome: Pathophysiological and clinical features]. Ter Arkh. 2017;89(1):123-127. doi: 10.17116/ terarkh2017891123-127. [Article in Russian].

11. Tokmachev RE, Kravchenko AYa, Budnevsky AV, et al.
[Activation of pro-inflammatory cytokines in patients with chronic heart failure comorbid with metabolic syndrome]. Kardiovaskulyarnaya Terapiya i Profilaktika. 2015;14(2):116117. [Article in Russian].

12. Budnevsky AV, Shurupova AD, Kravchenko AY, Tokmachev RE. [Clinical efficacy of acute respiratory viral infections prevention in patients with chronic heart failure]. Ter Arkh. 2019 Mar 30;91(3):36-41. doi: 10.26442/00403660. 2019.03.000111. [Article in Russian].

13. Tokmachev RE, Maksimov AV, Budnevsky AV. Device for cardiorespiratory analysis and method for assessing cardiorespiratory state. Invention patent RU 2637917 C, 07.12.2017. Application No. 2016148274. [In Russian].

14. Budnevsky AV, Pronin SS, Kontsevaya AV. Register of patients with chronic heart failure. Certificate of registration of the computer program RU 2019667733, 26.12.2019. Application No.2019666660. [In Russian]. 